\title{
Bacterial Community Research of Migratory Bird in Chifeng, Neimeng via High-Throughput Sequencing
}

\author{
Lin zheng \\ Jilin Agricultural University \\ Ling-Wei Zhu \\ the Academy of Military Medical Sciences \\ Jia-yao Guan \\ the Academy of Military Medical Sciences

\section{Ying Wang} \\ the Academy of Military Medical Seciences \\ Jie Jing \\ the Academy of Military Medical Seciences

\section{Bing Liang} \\ the Academy of Military Medical Seciences \\ Xue Ji \\ the Academy of Military Medical Seciences \\ Ping Chen ( $\nabla$ 1243377523@qq.com ) \\ Xue-Jun Guo ( $\square$ zl1243377523@outlook.com ) \\ the Academy of Military Medical Sciences
}

\section{Research article}

Keywords: migratory bird, Microbial community, High-throughput sequencing, 16S rDNA amplicon

Posted Date: May 28th, 2020

DOI: https://doi.org/10.21203/rs.3.rs-30522/v1

License: (c) (i) This work is licensed under a Creative Commons Attribution 4.0 International License. Read Full License 


\section{Abstract}

Background: In August 2018, a large number of migratory birds died in Chifeng, Neimeng. We were entrusted by local animal disease prevention and control center to collect the migratory bird epidemic materials and their living environmental water, and in 2019, we collect the local migratory bird stool and their living environmental water again. The bacterial communities in migratory bird epidemic materials, water and aquatic plants are profifiled by high-throughput sequencing of the V3-V4 hypervariable region of 16S rDNA gene.

Results: We found that the dominant phylum between migratory bird epidemic materials, water and aquatic plant were Proteobacteia, Bacteroidetes, Firmicutes, Fusobacteria and Verrucomicrobia in 2018. One year later, we found that the dominant phylum between migratory bird stool, water and aquatic plant were Proteobacteia, Firmicutes, Cyanobacteria, Bacteroidetes. The relative abundance among bacterial phylum notably differed between two years. The relative abundance of Fusobacteria and Verrucomicrobia were higher in samples in 2018, while that of Cyanobacteria was higher in water, 2019. The relative abundance of Fusobacteria in migratory bird epidemic materials began to decline in the later period over time. At genus level, the relative abundance of Vibrio, Clostridium and other patnogenic bacteria decreased markedly and disappeared in 2019. The salt content and pH show a downward trend.

Conclusions: Differences in diet and geographical location can lead to diversification in migratory bird intestinal flora. It is necessary to pay attention to diversification in intestinal flora of migratory birds, especially the abundance of vibrio in intestine. The overall structure of intestinal flora and relative abundance changes of various species are showed intuitively by $16 \mathrm{~S}$ rDNA amplicon. But comparing to PCR which using specific primers, the accuracy and sensitivity are relatively poor. In the case of purposeful detection, it can be used in combination with both 16S rDNA amplicon and PCR which using specific primers. They are more accurately, because of supplement each other.

\section{Background}

Migratory birds, a kind of wild animals that migrate long distances. They can carry pathogenic microorganisms from one place to another, and spread pathogenic microorganism by excretion [1, 2]. Migratory birds carry and transmit a wide range of influenza A viruses in nature, causing international attention to the migratory birds health problems [3]. Aquatic products are mostly carriers of Vibrio, and migratory birds eat aquatic products such as shellfish and fish [4]. It discoveried, migratory birds were new carriers of V. cholerae and V. parahaemolyticus [5, 6]. V. parahaemolyticus have caused three pandemics and V. cholerae caused seven times in human history. Until now, the seventh pandemic of V. cholerae have continued, and the seventh pandemic have evolved compared to previous pandemic, which make it difficult for the treatment of cholera [7-10]. In order to prevent the emergence of pandemic bacteria, we should be attention to state of the bacterial flora carried by migratory birds, and pay attention to whether they carry pandemic strains.

Migratory birds were malnutrition, wasting, diarrhea, and a large number of them were death in August 2018, Chifeng, Neimeng. Among dead birds were red duck, red-billed gull, black-winged sandpiper, silver gull, spot-billed Ducks and other precious birds. We found some birds with heart and intestine flatulence, bleeding in the intestinal mucosa, enlarged liver, but no abnormalities in the stomach and spleen by anatomized the migratory birds epidemic materials. We analyzed migratory bird epidemic materials and plankton in local environment by 16S rDNA amplicon, and we analyzed local healthy migratory bird stool and plankton from environment in 2109, once again. 


\section{Results}

\section{$\mathrm{pH}$, salt content, total vibrio count and total bacteria count of migratory birds habitat}

Table 1 showed the variations of $\mathrm{pH}$ and salt content during the sampling periods from 2018 to 2019 in Chifeng, Neimeng. Several environmental factors were measured during two years : salinity (0.87-0.008\%) and pH (9.1598.40), decreased slowly over time in Beihekou; salinity (0.076-0.017\%) and pH (9.12-8.88), decreased slowly over time in Ganggenghu. The pH of water samples from 2019, except for Beian and Nanyang, which showed a general decrease. The salt content of water samples from 2018 was higher than the second year. The count of total vibrio and bacteria was strong reduction from 2018 to 2019. The $\mathrm{pH}$ of Nanyang aquatic plants was slightly lower than Nanyang and the salt content was almost same to Nanyang, but the count of total of vibrio and bacteria were higher than Nanyang.

Table 1

$\mathrm{pH}$, salt content, total vibrio count and total bacteria count of migratory birds habitat

\begin{tabular}{|c|c|c|c|c|c|c|}
\hline name & type & time & $\mathrm{pH}$ & $\begin{array}{l}\text { salt content } \\
(\%)\end{array}$ & $\begin{array}{l}\text { total vibrio count } \\
\text { (cfu/mL) }\end{array}$ & $\begin{array}{l}\text { total bacteria count } \\
\text { (cfu/mL) }\end{array}$ \\
\hline Beihekou, chifeng & water & 2018 & 9.159 & 0.87 & 12000 & 320000 \\
\hline $\begin{array}{l}\text { Ganggenghu, } \\
\text { chifeng }\end{array}$ & water & 2018 & 9.12 & 0.076 & 20 & 6000 \\
\hline $\begin{array}{l}\text { Nanhekou, } \\
\text { chifeng }\end{array}$ & water & 2018 & 9.327 & 0.79 & 1840 & 214000 \\
\hline Beian, chifeng & water & 2019 & 9.46 & 0.63 & 100 & 300 \\
\hline Beihekou, chifeng & water & 2019 & 8.4 & 0.008 & 0 & 100 \\
\hline $\begin{array}{l}\text { Ganggenghu, } \\
\text { chifeng }\end{array}$ & water & 2019 & 8.88 & 0.017 & 0 & 300 \\
\hline Nanyang, chifeng & water & 2019 & 9.44 & 0.498 & 0 & 1100 \\
\hline Nanyang, chifeng & plant & 2019 & 8.79 & 0.51 & 1460 & 11900 \\
\hline
\end{tabular}

\section{High-Throughput Sequencing Profile}

High-throughput sequencing of 16S rDNA sequences was employed to determine bacterial community composition during the nursery phase of 36 samples from 2018 to 2019 in Chifeng. Table 2 showed the range of cleanreads for per sample was $55,013-64,774 ; 2,518$ OTUs were detected by clustering at a $97 \%$ identity threshold in 2018 . The sequences were randomly resampled at the minimum depth (42676 sequences per sample) among samples. To estimate the bacterial diversity in each sample, alpha diversity indices were calculated based on the OTUs. According to the Veen diagram (Figure 1), we found that there were 48 core OTUs from all samples in 2018, and 59 special OTUs from $\mathrm{H}$, there are 10 OTUs between $\mathrm{C}$ and S. There are more than 367 OTUs in S and $\mathrm{H}$. There were 75 
core OTUs from all samples in 2019, there were 53 OTUs between RS3 and RS2, and 12 OTUs between RS1 and RS3. Among them, there are 593 special OTUs in RS2 relative to RS3 and RS1. 


\begin{tabular}{|c|c|c|c|c|c|c|c|c|c|}
\hline Samples & Type & Time & $\begin{array}{l}\text { Clean } \\
\text { reads }\end{array}$ & OTUs & Coverage & $\begin{array}{l}\text { PD_Whole } \\
\text { tree index }\end{array}$ & $\begin{array}{l}\text { Chao } 1 \\
\text { index }\end{array}$ & $\begin{array}{l}\text { Shannon } \\
\text { index }\end{array}$ & $\begin{array}{l}\text { Simpson } \\
\text { Index }\end{array}$ \\
\hline A2G & $\begin{array}{l}\text { visceral } \\
\text { organs }\end{array}$ & 2018 & 61982 & 220 & 0.999 & 18.793 & 223.600 & 5.858 & 0.956 \\
\hline $\mathrm{A} 2 \mathrm{~F}$ & $\begin{array}{l}\text { visceral } \\
\text { organs }\end{array}$ & 2018 & 55643 & 178 & 0.998 & 19.809 & 316.000 & 2.766 & 0.724 \\
\hline A3C & $\begin{array}{l}\text { intestinal } \\
\text { tracts }\end{array}$ & 2018 & 56719 & 73 & 0.999 & 9.830 & 102.200 & 2.804 & 0.811 \\
\hline A3F & $\begin{array}{l}\text { visceral } \\
\text { organs }\end{array}$ & 2018 & 57277 & 280 & 0.999 & 25.995 & 326.077 & 4.182 & 0.873 \\
\hline A5G & $\begin{array}{l}\text { visceral } \\
\text { organs }\end{array}$ & 2018 & 61530 & 342 & 0.999 & 27.463 & 365.625 & 5.356 & 0.924 \\
\hline A5F & $\begin{array}{l}\text { visceral } \\
\text { organs }\end{array}$ & 2018 & 55914 & 125 & 0.999 & 15.558 & 233.067 & 2.797 & 0.766 \\
\hline A5C & $\begin{array}{l}\text { intestinal } \\
\text { tracts }\end{array}$ & 2018 & 57872 & 207 & 0.998 & 19.804 & 241.333 & 2.347 & 0.695 \\
\hline A8G & $\begin{array}{l}\text { visceral } \\
\text { organs }\end{array}$ & 2018 & 64774 & 246 & 0.999 & 19.584 & 248.545 & 5.195 & 0.909 \\
\hline A8F & $\begin{array}{l}\text { visceral } \\
\text { organs }\end{array}$ & 2018 & 55464 & 222 & 0.999 & 16.083 & 249.00 & 5.615 & 0.951 \\
\hline $\mathrm{A} 8 \mathrm{C}$ & $\begin{array}{l}\text { intestinal } \\
\text { tracts }\end{array}$ & 2018 & 55766 & 248 & 0.999 & 24.130 & 275.00 & 3.210 & 0.698 \\
\hline A11G & $\begin{array}{l}\text { visceral } \\
\text { organs }\end{array}$ & 2018 & 58124 & 249 & 0.999 & 22.561 & 266.391 & 3.266 & 0.824 \\
\hline $\mathrm{A} 11 \mathrm{~F}$ & $\begin{array}{l}\text { visceral } \\
\text { organs }\end{array}$ & 2018 & 63193 & 246 & 0.999 & 19.574 & 249.077 & 4.771 & 0.906 \\
\hline A11C & $\begin{array}{l}\text { intestinal } \\
\text { tracts }\end{array}$ & 2018 & 60274 & 201 & 0.999 & 18.926 & 234.583 & 3.274 & 0.830 \\
\hline A12C & $\begin{array}{l}\text { intestinal } \\
\text { tracts }\end{array}$ & 2018 & 55013 & 299 & 0.999 & 24.563 & 303.903 & 4.939 & 0.912 \\
\hline A13G & $\begin{array}{l}\text { visceral } \\
\text { organs }\end{array}$ & 2018 & 57532 & 244 & 0.999 & 19.295 & 296.125 & 5.555 & 0.959 \\
\hline A13F & $\begin{array}{l}\text { visceral } \\
\text { organs }\end{array}$ & 2018 & 61801 & 330 & 0.999 & 23.465 & 377.045 & 6.376 & 0.968 \\
\hline A13Y & $\begin{array}{l}\text { visceral } \\
\text { organs }\end{array}$ & 2018 & 56972 & 124 & 0.999 & 13.050 & 135.333 & 0.803 & 0.142 \\
\hline $\mathrm{A} 13 \mathrm{C}$ & $\begin{array}{l}\text { intestinal } \\
\text { tracts }\end{array}$ & 2018 & 59227 & 271 & 0.999 & 22.517 & 288.375 & 3.423 & 0.773 \\
\hline A14G & $\begin{array}{l}\text { visceral } \\
\text { organs }\end{array}$ & 2018 & 57017 & 284 & 0.999 & 21.318 & 291.231 & 5.255 & 0.918 \\
\hline A14C & $\begin{array}{l}\text { intestinal } \\
\text { tracts }\end{array}$ & 2018 & 58623 & 217 & 0.999 & 20.869 & 246.527 & 2.432 & 0.684 \\
\hline A18C & intestinal & 2018 & 58824 & 136 & 0.999 & 14.633 & 193.143 & 2.590 & 0.763 \\
\hline
\end{tabular}




\begin{tabular}{|c|c|c|c|c|c|c|c|c|c|}
\hline A19C & $\begin{array}{l}\text { intestinal } \\
\text { tracts }\end{array}$ & 2018 & 57973 & 391 & 0.998 & 33.261 & 432.176 & 5.813 & 0.957 \\
\hline $\mathrm{H} 1 \mathrm{C}$ & $\begin{array}{l}\text { aquatica } \\
\text { plant }\end{array}$ & 2018 & 58646 & 514 & 0.997 & 44.744 & 679.788 & 5.566 & 0.955 \\
\hline $\mathrm{H} 2 \mathrm{C}$ & $\begin{array}{l}\text { aquatica } \\
\text { plant }\end{array}$ & 2018 & 56012 & 414 & 0.996 & 38.446 & 624.898 & 4.254 & 0.884 \\
\hline H3C & $\begin{array}{l}\text { aquatica } \\
\text { plant }\end{array}$ & 2018 & 56892 & 805 & 0.997 & 66.919 & 877.532 & 7.359 & 0.986 \\
\hline H1S & $\begin{array}{l}\text { lake } \\
\text { water }\end{array}$ & 2018 & 63704 & 807 & 0.997 & 64.380 & 835.718 & 7.379 & 0.987 \\
\hline $\mathrm{H} 2 \mathrm{~S}$ & $\begin{array}{l}\text { lake } \\
\text { water }\end{array}$ & 2018 & 62029 & 712 & 0.996 & 55.820 & 855.284 & 6.536 & 0.973 \\
\hline H3S & $\begin{array}{l}\text { lake } \\
\text { water }\end{array}$ & 2018 & 62478 & 815 & 0.996 & 60.894 & 966.074 & 6.881 & 0.980 \\
\hline RS1.1 & feaces & 2019 & 14293 & 116 & 0.994 & 13.042 & 261.091 & 2.386 & 0.727 \\
\hline RS1.2 & feaces & 2019 & 22662 & 85 & 0.997 & 8.135 & 95.000 & 1.807 & 0.623 \\
\hline RS1.3 & feaces & 2019 & 19156 & 219 & 0.995 & 16.775 & 211.766 & 3.316 & 0.804 \\
\hline RS2.1 & $\begin{array}{l}\text { lake } \\
\text { water }\end{array}$ & 2019 & 15721 & 234 & 0.995 & 22.538 & 242.025 & 4.585 & 0.910 \\
\hline RS2.2 & $\begin{array}{l}\text { lake } \\
\text { water }\end{array}$ & 2019 & 26449 & 301 & 0.992 & 21.280 & 291.936 & 2.489 & 0.653 \\
\hline RS2.3 & $\begin{array}{l}\text { lake } \\
\text { water }\end{array}$ & 2019 & 29696 & 443 & 0.989 & 33.565 & 439.889 & 3.658 & 0.736 \\
\hline RS2.4 & $\begin{array}{l}\text { lake } \\
\text { water }\end{array}$ & 2019 & 15817 & 440 & 0.990 & 32.506 & 450.808 & 4.843 & 0.848 \\
\hline RS3.1 & $\begin{array}{l}\text { aquatica } \\
\text { plant }\end{array}$ & 2019 & 48599 & 645 & 0.984 & 35.937 & 594.720 & 4.349 & 0.783 \\
\hline
\end{tabular}

Table 2

Alpha Diversity Index statistical table

Bacterial diversity, estimated by the PD_Whole tree index, varied from 7.830-966.074 (mean $=53.951$ ), the Chao1 index, varied from 102.200-966.074 (mean = 383.345), the Shannan index, varied from 0.803-7.379 (mean $=4.522)$ and the Simpson index, varied from 0.142-0.986 (mean $=0.847)$ in 2018. There was significant difference in alpha diversity indices between three kinds of samples in 2018 ( $p<0.05, t$ test). But in 2019, the range of cleanreads for per sample was $14,293-48,599 ; 1,351$ OTUs were detected by clustering at a $97 \%$ identity threshold. To estimate the bacterial diversity in each sample, alpha diversity indices were calculated based on the OTUs. Bacterial diversity, estimated by the PD_Whole tree index, varied from 8.135-35.937 (mean = 22.972), the Chao1 index, varied from 95594.720 (mean = 323.404), the Shannan index, varied from 1.807-4.843 (mean = 3.429) and the Simpson index, varied from 0.623-0.910 (mean $=0.761$ ) in 2018. There was no significant difference in alpha diversity indices between three kinds of samples in 2019 ( $p>0.05, t$ test) (Table 2$)$. 


\section{Bacterial Community Composition and Beta Diversity}

At phylum level, Proteobacteia (45.17\%), Bacteroidetes (21.73\%), Firmicutes (20.25\%), Fusobacteria (9.96\%) and Verrucomicrobia (2.89\%) were the dominant bacterial phylum in 2018. But in 2019, Proteobacteia (69.01\%), Firmicutes (16.98\%), Cyanobacteria (10.27\%) and Bacteroidetes (3.73\%) were the dominant bacterial phylum ( Fig. 2, Table 3 ). we found that the abundance of Proteobacteia increased markedly in 2019, while the abundance of Bacteroidetes and Firmicutes decreased. At genus level, there was significant difference in main 10 genus of samples in 2018 and 2019. The results indicated a noticeable difference in bacterial community between the environmental samples ( water and aquatic plant) and migratory bird samples (epidemic material or stool) ( Supplement Figure S1, Table 3 ). 
Table 3

Main 10 of samples at genus level statistical table

\begin{tabular}{|c|c|c|c|c|}
\hline Name & & Time & $\begin{array}{l}\text { Proportion in the } \\
\text { sample (\%) }\end{array}$ & Mainly separated samples \\
\hline Fusobacterium & Fusobacteria & 2018 & 7 & intestinal tracts, visceral organs \\
\hline Plesiomonas & Proteobacteia & 2018 & 9.52 & visceral organs, intestinal tracts \\
\hline Bacteroides & Bacteroidetes & 2018 & 17.87 & visceral organs, intestinal tracts \\
\hline Cetobacterium & Fusobacteria & 2018 & 2.95 & intestinal tracts, visceral organs \\
\hline Wohlfahrtiimonas & Proteobacteia & 2018 & 3.31 & visceral organs, intestinal tracts \\
\hline Escherichia/Shigella & Proteobacteia & 2018 & 4.76 & visceral organs, intestinal tracts \\
\hline Aeromonas & Proteobacteia & 2018 & 6.26 & $\begin{array}{l}\text { visceral organs, intestinal tracts, } \\
\text { aquatica plant, lake water }\end{array}$ \\
\hline Clostridium XI & Firmicutes & 2018 & 5.87 & visceral organs, intestinal tracts \\
\hline Vibrio & Proteobacteia & 2018 & 7.73 & $\begin{array}{l}\text { visceral organs, aquatica plant, } \\
\text { intestinal tracts, lake water }\end{array}$ \\
\hline $\begin{array}{l}\text { Clostridium sensu } \\
\text { stricto }\end{array}$ & Firmicutes & 2018 & 10.59 & $\begin{array}{l}\text { intestinal tracts, visceral organs, lake } \\
\text { water }\end{array}$ \\
\hline Enterobacter & Proteobacteia & 2019 & 18.69 & feaces \\
\hline Acinetobacter & Proteobacteia & 2019 & 12.88 & aquatica plant \\
\hline Hydrogenophaga & Proteobacteia & 2019 & 10.5 & aquatica plant, lake water \\
\hline Loktanella & Proteobacteia & 2019 & 11.93 & lake water, aquatica plant, feaces \\
\hline Trichococcus & Firmicutes & 2019 & 15.02 & feaces \\
\hline Psychrobacter & Proteobacteia & 2019 & 8.01 & lake water, feaces \\
\hline $\begin{array}{l}\text { Unidentified } \\
\text { cyanobacteria }\end{array}$ & Cyanobacteria & 2019 & 10.27 & feaces \\
\hline Stenotrophomonas & Proteobacteia & 2019 & 7 & feaces \\
\hline Dinghuibacter & Bacteroidetes & 2019 & 3.73 & feaces \\
\hline Proteiniclasticum & Firmicutes & 2019 & 1.97 & lake water, aquatica plant \\
\hline
\end{tabular}

According to the weighted unifrac PCoA ( Fig. 3), A2F, A11G, A18C and H2C were clustered together, which implied a high similarity among bacterial communities from different samples. Compared to 2018, stool samples and environmental samples were scattered distribution, didn't clustered together. Only RS2.4 and RS3.1 were clustered together ( Supplement Table S1).

The samples OTUs could be divided into three types in 2018 by UPGMA ( Fig. 4). We found that some migratory bird epidemic materials were closely related to plankton from environment. The samples OTUs could also be divided into two categories in 2019 , but we found that genetic relationship in figure that feces had close relationship with other planktonic bacteria, except water planktonic bacteria RS2.1 and RS2.3. 
According to the heatmap (Fig. 5 ), the abundance of Plesiomonas in A13Y was high in 2018, which made cluster distance between A13Y and others was far. The samples showed a diverse structure, and each sample with its own unique higher abundance genus in 2019. The LEfSe showed resulted in significant differences in the samples from 2018 to 2019, See Supplement Figure S2 and Supplement Table S2 for details.

\section{Detection of pathogenic Vibrio}

Vibrio was identified by PCR as V. cholerae and V. metschnikovii. V. cholerae identified by PCR did not contain CTX, rtxA, but contained hlyA and was identified as non-01 and $0139 \mathrm{~V}$. cholerae by serum in 2018. However, Vibrio was identified as V. metschnikovii by PCR, and V. cholerae was not detected in 2019 ( Table 4 ).

Table 4

Identification primers of V. cholerae and V. metschnikovii

\begin{tabular}{|c|c|c|c|c|}
\hline Primer & $\begin{array}{l}\text { Target } \\
\text { gene }\end{array}$ & Sequence ( $\left(3^{\prime}\right.$ to $\left.5^{\prime}\right)$ & Amplicon(bp) & $\begin{array}{l}\text { Annealing temperature } \\
\left({ }^{\circ} \mathrm{C}\right)\end{array}$ \\
\hline ompW-F & \multirow[t]{2}{*}{ ompW } & CACCAAGAAGGTGACTTTATTGTG & \multirow[t]{2}{*}{588 bp } & \multirow[t]{2}{*}{55} \\
\hline ompW-R & & GAACTTATAACCACCCGCG & & \\
\hline $\operatorname{ctxA}-\mathrm{F}$ & \multirow[t]{2}{*}{$\operatorname{ctxA}$} & CTCAGACGGGATTTGTTAGGCACG & \multirow[t]{2}{*}{301 bp } & \multirow[t]{2}{*}{55} \\
\hline $\operatorname{ctxA}-\mathrm{R}$ & & TCTATCTCTGTAGCCCCTATTACG & & \\
\hline tcpA-F & \multirow[t]{2}{*}{ tcpA } & TGCTGTCMGTRYCGCACCAG & \multirow[t]{2}{*}{1185 bp } & \multirow[t]{2}{*}{55} \\
\hline tcpA-R & & CGGCAGAGGCCARRATCGCCT & & \\
\hline hlyA-F & \multirow[t]{2}{*}{ hlyA } & GGCAAACAGCGAAACAAATACC & \multirow[t]{2}{*}{ 738/727 bp } & \multirow[t]{2}{*}{55} \\
\hline hlyA-R & & GCTCAGCGGGCTAATACGRTT & & \\
\hline 01-rfb-F & \multirow[t]{2}{*}{ 01-rfb } & СССАААТGССАСТААССТTG & \multirow[t]{2}{*}{572 bp } & \multirow[t]{2}{*}{50} \\
\hline 01-rfb-R & & GGTCATCTGTAAGTACAAC & & \\
\hline $\begin{array}{l}\text { O139-rfb- } \\
\text { F }\end{array}$ & \multirow[t]{2}{*}{ 0139-rfb } & AGCCTCTTTATTACGGGTGG & \multirow[t]{2}{*}{449 bp } & \multirow[t]{2}{*}{55} \\
\hline $\begin{array}{l}\text { 0139-rfb- } \\
\text { R }\end{array}$ & & GTCAAACCCGATCGTAAAGG & & \\
\hline $\operatorname{chxA-F}$ & \multirow[t]{2}{*}{$\operatorname{ch} \times A$} & GAAATATCATCGAGGTGCCT & \multirow[t]{2}{*}{$1072 / 1090$ bp } & \multirow[t]{2}{*}{50} \\
\hline $\operatorname{ch} \times A-R$ & & GCAACTTCAGCGTGAGTTGC & & \\
\hline infC-F & \multirow[t]{2}{*}{ infC } & AGCATGACCAAGCTGCTCTT & \multirow[t]{2}{*}{260} & \multirow[t]{2}{*}{60} \\
\hline infC-R & & GCAAATATCCGACAGCACCATT & & \\
\hline
\end{tabular}

\section{Discussion}

In recent years, the research on the intestinal flora had gradually increased, but the research on the structure of migratory animals intestinal flora, except swans and ducks., was still relatively poor. Dietary habits of animals had a great relationship with the habitat, plankton from habitat could be used as the indicator of migratory birds health 
status $[11,12]$. We found that more than 20 kinds of known phylum and more than 1300 kinds of known genus could be carried in migratory birds by 16S rDNA analysis of migratory birds epidemic material and stool ( Supplement Table S3 ). Our results were consistent with studies on the intestinal bacteria of swan and mallard, the dominant phylum of them were Proteobacteia, followed by Bacteroidetes and Firmicutes [13, 14]. At the same time, the water environment as the main source of migratory bird diet, it played an important role in the composition of migratory bird gut microbiota [15]. The results implied that the microbial species richness in environment was higher than that in migratory birds, there were differences between the composition structure of the microbiota, migratory bird epidemic materials and environmental samples in 2018, were no significant. The differences in the composition of the microbiota between various samples were not significant in 2019 , while the differences might be ascribed to changes in relative abundance.

Except common phylum in intestinal tract, the relative abundance of Fusobacteria and Verrucomicrobia in epidemic materials was relatively higher than other samples, while the relative abundance of them in stool was poor. Among them, the relative abundance of Fusobacteria in migratory birds intestine was relatively higher than that in other samples in 2018, and the relative abundance in the habitat was extremely poor, which was the same as habitat in 2019. Fusobacteria was not the main phylum in environment, but they were carried by migratory birds from other places to there. It was well colonized in migratory birds intestinal tract, and little planktonic bacteria have formed. This might be one of the reasons why the relative abundance of Fusobacteria was greatly reduced. Gut microbiota was certain differences between feces and intestines of migratory birds. However, Fusobacteria should not be the main phylum in the intestine. When Fusobacteria was significantly elevated in the intestine, it would cause intestinal flora imbalance, which may cause diarrhea or other chronic diseases [16].

We also found that Fusobacteria caused significant difference between intestinal samples and other samples by LEfse, 2018. Fusobacterium and Cetobacterium were Fusobacteria, and the relative abundance was relatively higher than others at genus level of samples in 2018. Heatmap showed that abundance of Fusobacterium and Cetobacterium in Bird N0.3 was higher than other birds. Fusobacterium and Cetobacterium were detected in bird N0.3 intestine at same time, and abundance of them was relatively high, and Cetobacterium was also detected in bird NO.3 lungs, which also had a high abundance.

However, the relative abundance of Fusobacteria in epidemic materials began to decline in the later period over time. Abundance of Fusobacterium and Cetobacterium in birds NO.18 and NO.19 in intestine was little, and it was not the dominant genus of birds N0.18 and N0.19. We believed that other phylum have begun to breed, especially Proteobacteia, resulting in the relative abundance of Fusobacteria reduced. We found that abundance of Vibrio, Aeromonas and Plesiomonas in bird N0.18 intestine was relatively higher than others, and abundance of Bacteroides, Megamonas, Lactococcus and Parabacteroides in bird N0.19 intestine was relatively higher than others by heatmap. Among them, the relative abundance of Vibrio, Aeromonas, Plesiomonas and Bacteroides was also higher, which was the dominant genus, and they were Proteobacteia at phylum level. There were significant differences from the organ samples and other samples, because of Plesiomonas. There was a relatively high abundance in bird N0.13 pancreas, but the relative abundance in environment was also extremely low (Fig. 5 and Table 3 ). Vibrio and Aeromonas were detected in migratory bird habitats and epidemic materials in 2018. Except for bird NO.2 lung and bird NO.18 intestine, the abundance of Vibrio in the remaining samples was slightly higher than that of Aeromonas ( Fig. 5 ). In 2019, the abundance of Vibrio and Aeromonas decreased significantly. Abundance of Aeromonas in water was higher than that of other samples, while Vibrio only with a lower abundance in stool. And in 2018, we isolated a large number of non-01/0139 V. cholerae and V. metschnikovii in epidemic materials. It's interesting that we only found Vibrio with extremely low abundance in migratory feces by 16S rDNA 
amplicon, but we found a large number of V. metschnikovii in migratory bird feces and water in 2019 by PCR, which with specific primer. There were differences with the results of 16S rDNA amplicon. We thought that the bacteria were enriched after feces were streaked onto the solid medium. And, during the process of DNA binding with universal primers, defective combintion would also lead to deviations in the results [17]. The PCR detection of specific primers used specific primers of V. metschnikovii for identification, and there would be no defective combintion of bacterial DNA and primers [18].

The abundance of Vibrio on surface of aquatic plants was higher than water in 2018. It might be a large number of plankton in water. And Vibrio without advantage in abundance. Abundance of Vibrio in lungs was higher than intestines and other organs. Vibrio infection was usually caused by eating food contaminated with Vibrio, which changed the permeability of the small intestinal epithelial cells, resulting in abnormal $\mathrm{Na} / \mathrm{K}^{+}$pumps and diarrhea $[19,20]$.

If migratory birds ate foods infected with V. cholera or V. metschnikovii, which caused V. cholerae to be infected in intestine, and then carried to Chifeng, the intestine was the initial invasion site of bacteria. The abundance of bacteria should be the highest, but the abundance of V. cholera in lungs was high. We speculated that V. cholera were not invaded by the intestine, they might be invaded by the lungs, and then spread throughout body. Due to the relative abundance, it was not ruled out that relative abundance of Fusobacteria in the intestine was higher, and relative abundance of Vibrio in Proteobacteia was lower. We could also find the relative abundance of Fusobacteria in bird N0.18 intestine, and abundance of Vibrio increased by heatmap. We speculated that Vibrio was also present in other birds intestines, but it was less than Fusobacteria abundance. And we also verified our conjecture by separated and identified Vibrio in samples. The abundance of Vibrio in water was relatively poor, and biofilm formation capacity of the bacteria may be strong, resulting in more Vibrio on surface of aquatic plants and relatively few plankton in water. By analyzing the dominant genus in epidemic materials in 2018, it was closer to the dominant bacterial structure of fish [21]. It might be caused by migratory birds ate contaminated fish, opportunistic bacteria invasion, resulting in poor absorption of nutrients, weight loss, intestinal mucosal bleeding and other conditions.

Salinity and $\mathrm{pH}$ were indicators to assess whether Vibrio could grow well in one place. For V. cholerae disappeared in 2019, we compared the indicators of local water in these two years [22].

It was found that both $\mathrm{pH}$ and salinity had decreased, but $\mathrm{pH}$ and salinity were also within the range of growth for V. cholerae in 2019. And there are a large number of V. metschnikovii from samples in 2019. It indicated that Chifeng, which suitable for the growth for Vibrio. The decrease of $\mathrm{pH}$ and salinity was not the reason for the disappearance of V. cholerae, it might be carried here by migratory birds. Poultry was susceptible for V. metschnikovii, first discovered in a bird epidemic materials [23]. But, it has not aroused social concern. There was no international report on the pathogenic ability of V. metschnikovii. It with higher adaptability than other kinds of Vibrio.

V. cholerae without any direct lethal toxin, only contained $h l y A$. It might be opportunistic pathogen in migratory birds and didn't cause migratory birds death rapidly in a short time. It could cause intestinal mucosal bleeding, which was consistent with the pathological characteristics of migratory birds.

Cyanobacteria was the dominant phylum in water, 2109 and the relative abundance of the Cyanobacteria had dropped significantly in water, 2108. Cyanobacteria was a common phylum in water, and it was an indicator to assess whether water was polluted. It indicated that there was cyanobacteria pollution in the water, Chifeng [24, 25]. 
We also found that Cyanobacteria which was to be significantly different between water and stool at phylum level, and that was unidentified_Cyanobacteria at genus level. However, Enterobacter was to be significantly different between feaces and water at genus level. Although Cyanobacteria was polluted in water, it was not impact on migratory birds.

\section{Conclusions}

This study provided basic knowledge of the relationship between environmental microbiota and the migratory birds in aquaculture using high-throughput sequencing. In our study, Proteobacteia, Bacteroidetes, Firmicutes were the dominant phylum of gut microbiota in migratory birds from 2018 to 2019 . Migratory migratory birds with long distance, it caused gut microbiota to complicate. And it could carry pathogenic bacteria to transfer.

Neimeng, as a natural bacterial storage, was not only suitable for various rare animals to survive here, but also suitable for various microorganisms to survive here. Differences in diet and geographical location could lead to change migratory bird gut microbiota. It was necessary to pay attention to change in migratory birds intestinal flora, especially the abundance of vibrio in intestine.

It could intuitively reflect the relative abundance changes of entire gut microbiota and various species in it by $16 \mathrm{~S}$ rDNA amplicon. But its accuracy and sensitivity were poor compared to PCR, which using specific primers. If the relative abundance of the species was very poor, it was eliminated. Abundance of some pathogenic bacteria was very low in organism before it broke out. Once it was eliminated, it would cause a lot of unnecessary trouble and might cause a pandemic. Therefore, 16S rDNA amplicon and PCR, which using specific primers could be used simultaneously as complementary and more accurate in case of purposeful detection.

\section{Methods}

\section{Sample Collection}

Consequent two years of Chifeng with migratory bird migration backgrounds were selected for sampling. Water samples were collected from seven different points of lake water from 2018 to 2019 during the rearing period. Seven water samples were collected: H1S - H2S ( 2018 ) and RS2.1-RS2.3 ( 2019 ). And we collected four aquatic plant samples from same lake. Four aquatic plant samples were collected: H1C-H2C ( 2018 ) and RS3.1 ( 2019 ). Multi-sample mixing method for sampling stool samples. And 24 stool samples were collected, per eight samples were mixed into one sample: RS1.1 - RS1.3 ( 2019 ). According to morphological observations, the epidemic materials were divided into two stages: intestinal tracts ( A3C, A5C, A8C, A11C, A12C, A13C, A14C, A18C, A19C ) and visceral organs ( A2G, A2F, A3F, A5G, A5F, A8G, A8F, A11G, A11F, A13G, A13F, A13Y, A14G ) in 2018 (Table 1). Water samples were fifiltered through a $0.22 \mu \mathrm{m}$ polycarbonate membrane fifilter (Millipore) to collect bacterial cells. The membrane fifilters were transferred to a $50 \mathrm{~mL}$ sterile centrifuge tube and stored at $-80^{\circ} \mathrm{C}$ until DNA extraction. Alkalinity and $\mathrm{pH}$ were determined using $\mathrm{pH}$ meter and salinity were determined using conductivity meter.

\section{Extraction of genome DNA and library construction}

Genomic DNA of the water samples, aquatic plant samples, epidemic material samples and stool samples were extracted respectively from the membrane fifilters with Water DNA Kit, Plant DNA Kit, (OmegaBiotek), Tissue DNA Kit and Stool DNA Kit. The bacterial communities in the samples were profifiled by highthroughput sequencing of 


\section{Data Processing and Bioinformatics Analysis}

The effective sequences were clustered into OTUs with Usearch with a 97\% identity threshold. Before downstream analysis, all samples were re-sampled randomly at the minimum depth of all samples to minimize the biases of unequal sequencing depth. Taxonomic information of each OTU was assigned using the Ribosomal Database Project classififier (Version 2.2). After classification, according to the number of sequences in each OTU, the OTU abundance table is obtained.

Sequences were clustered followed by chimera filtering, OTUs for species classification, each OTU is considered to represent a species. We picked a representative sequences for each OTU and used the RDP (RDP, http://rdp.cme.msu.edu)classifier to annotate taxonomic information for each representative sequence [27, 28]. Based on OTU abundances and taxonomic annotation of OTUs, we obtained relative abundance profiles at the phylum, class, order, family, genus, and species. This makes it easy to understand the overall situation of each classification level annotated.

The abundance of different species, species clustering, and sample clustering information for sample are reflected by color gradients of heatmap.It drawed by heatmap.2, gplots package, R.

In the molecular evolution research, studying the evolutionary relationship of the system. Through phylogenetic relationship to reveal the difference between a certain level of OTUs sequence, combined with the species annotation information represented by each OTUs sequence, then built a evolution tree. According to the results of species classification, the dominant species were selected.

The abundances of main 10 genus were used for constructing species classification tree, abundance differences and evolution relationships of dominant species in single or multiple samples were understood from the entire classification system. We calculated the value of sample Alpha Diversity Index by QIIME software made the corresponding dilution curve.

Dilution curve was a curve, using the relative proportions of various known OTUs in measured 16S rDNA sequence to calculate the expected value of each Alpha diversity index when extracting $n$ ( $n$ is less than the total number of measured Reads sequences), and then based on a set of $n$ values (it's generally a set of equivariance series less than the total sequence number) and the expected value of the corresponding Alpha diversity index [29]. And we made Alpha Diversity Index statistical table. In addition, the 16S rDNA gene amplicon sequence data were also analyzed based on weighted UniFrac distance, alpha diversity (PD index, Chao 1 index, Shannon index, Simpson index) and principal coordinates analysis (PCoA). According to OUTs evolutionary relationship in the sample, UPMGA was used to draw an evolutionary tree to analyze the relationship between the samples.

LEfSe analysis: LEfSe uses linear discriminant analysis (LDA) to estimate the magnitude of the effect of each component (species) abundance on the difference effect, and find out the communities or species that have a significant difference in sample division. we uses LEfSe Tools in this study [30].

\section{List Of Abbreviations}


PCR: Polymerase chain reaction; OTU: operational taxonomic unit; PCoA: Principal Coordinates Analysis; LEfSe: Linear discriminant analysis EffectSize; UPMGA: Unweighted pair group method with arithmetic mean.

\section{Declarations}

\section{Ethics approval and consent to participate}

All migratory bird stool samples were collected under the supervision by the Wild Animal Sources and Diseases Inspection Station, National Forestry and Grassland Bureau, and did not cause any harm to the animals. All migratory bird epidemic material samples were provided by the local animal disease prevention and control center for bacteriological examination. The experimental protocol was established, according to the ethical guidelines of Helsinki Declaration and was approved by the Laboratory Animal Welfare and Ethics Committee of the Key Laboratory of Jilin Province for Zoonosis Prevention and Control (AMMS - 11-2020 - 11).

\section{Consent for publication}

Not Applicable.

\section{Availability of data and material}

All data generated or analysed during this study are available from the corresponding author on reasonable request.

\section{Competing interests}

The authors declare that they have no competing interests.

\section{Funding}

Funding for study design, data collection and data generation was provided by the National Key Research and Development Programme of China ( N0.2016YFD0501305). Publication costs are also funded by the National Key Research and Development Programme of China ( NO.2016YFD0501305 ).

\section{Authors' contributions}

PC, XJG conceived, directed, and carried out the study. LWZ, YW, JJ and BL prepared samples for sequence analysis; XJ, JYG and LZ acquired samples, and other people analyzed the data. All authors have read and approved the final manuscript.

\section{Acknowledgements}


We are grateful to members of the Institute of Military Veterinary Science, the Academy of Military Medical Sciences/ The Key Laboratory of Jilin Province for Zoonosis Prevention and Control for help and suggestions. We also acknowledge the Jilin Agricultural University.

\section{References}

1. Dijk JG, Verhagen JH, Wille M, Waldenström J: Host and virus ecology as determinants of influenza A virus transmission in wild birds Curr. Opin. Virol. 2018, 28: 26-36.

2. Allarda SM, Callahan MT, Bui A, et al: Creek to Table: Tracking fecal indicator bacteria, bacterial pathogens, and total bacterial communities from irrigation water to kale and radish crops Sci. Total Environ. 2019, 666: 461471.

3. Alvarez $\mathrm{P}$, Mattiello R, Rivailler $\mathrm{P}$, et al: First isolation of an H1N1 avian influenza virus from wild terrestrial nonmigratory birds in Argentina Virology 2010,396: 76-84.

4. Jusserand BM, Copin S, Bris LC, et al: Vibrio species involved in seafood-borne outbreaks (Vibrio cholerae, V. parahaemolyticus and $V$. vulnificus): Review of microbiological versus recent molecular detection methods in seafood products Crit. Rev. Food Sci. Nutr. 2019,59: 597-610.

5. Miyasaka J, Yahiro S, Arahira Y, et al: Isolation of Vibrio parahaemolyticus and Vibrio vulnifificus from wild aquatic birds in Japan Epidemiol. Infect. 2006, 134:780-785.

6. Shitrit LS, Izhaki I, Arakawa E, et al: Wild waterfowl as potential vectors of Vibrio cholerae and Aeromonas species Trop. Med. Int. Health 2018, 23: 758-764.

7. Chao G, Wang F, Zhou X, et al: Origin of Vibrio parahaemolyticus 03:K6 pandemic clone Int. J. Food Microbiol. 2011,145(2-3):459-63.

8. Boyd EF, Cohen AL, Naughton LM, et al: Molecular analysis of the emerquence of pandemic Vibrio parahaemolyticus BMC Microbiol. 2008, 8:110.

9. Hu D, Liu B, Feng L, Ding P, et al: Origins of the current seventh cholera pandemic Proc. Natl. Acad. Sci. 2016, 113(48): 7730-7739

10. Ramamurthy T, Mutreja A, Weill FX, et al: Revisiting the Global Epidemiology of Cholera in Conjuction With the Genomics of Vibrio cholerae Front. Public Health. 2019, 7:203.

11. Wright RT and Coffin RB: Planktonic bacteria in estuaries and coastal waters of northern massachusetts: spatial and temporal distribution Mar. Ecol. Prog. 1983, 11(3): 205-216.

12. Wu Y, Yang Y, Cao L, et al: Habitat environments impacted the gut microbiome of long-distance migratory swan geese but central species conserved Sci. Rep. 2018, 8(1):13314.

13. Wang $\mathrm{S}$, Chen $\mathrm{L}, \mathrm{He} \mathrm{M}$, et al: Different rearing conditions alter gut microbiota composition and host physiology in Shaoxing ducks Sci. Rep. 2018, 8(1):7387.

14. Xiong J, Zhu J, Dai W, et al: Integrating gut microbiota immaturity and disease-discriminatory taxa to diagnose the initiation and severity of shrimp disease Environ. Microbiol. 2107, 19:1490-1501.

15. Risely A, Waite DW, Ujvari B, et al: Active migration is associated with specific and consistent changes to gut microbiota in Calidris shorebids J. Anim. Ecol. 2018, 87(2): 428-437.

16. Sears CL: The who, where and how of fusobacteria and colon cancer Elife. 2018, 7.

17. Masella AP, Bartram AK, Truszkowski JM, et al: PANDAseq: paired-end assembler for illumina sequences $B M C$ Bioinf. 2012, 13: 31. 
18. Cao J, Xu J, Zheng Q, et al: Rapid detection of Vibrio metschnikovii in aquatic products by real-time PCR Folia Microbiol. 2010, 55(6): 607-613.

19. Khouadja S, Suffredini E, Baccouche B, et al: Occurrence of virulence genes among Vibrio cholerae and Vibrio parahaemolyticus strains from treated wastewaters Environ. Monit. Assess. 2014, 186(10): 6935-6945.

20. Sánchez J, Holmgren $\mathrm{J} \mathbb{}$ Cholera toxin structure, gene regulation and pathophysiological and immunological aspects Cell. Mol. Life Sci. 2008, 65(9):1347-1360.

21. Nayak, Sukanta K: Role of gastrointestinal microbiota in fish Aquacult. Res. 2010, 41(11): 1553-1573.

22. DeAngelis CM, Saul-McBeth J, Matson JS: Vibrio responses to extracytoplasmic stress Environ. Microbiol. Rep. 2018, 10(5): 511-521.

23. Lee JV, Donovan TJ, Furniss AL: Characterization, Taxonomy, and Emended Description of Vibrio metschnikovii Int. J. Syst. Evol. Microbiol. 1978, 28(1): 99-111.

24. He X, Liu YL, Conklin A, et al: Toxic cyanobacteria and drinking water: Impact, detection, and treatment Harmful Algae. 2016, 54:174-193.

25. Lee EH, Chua B, Son A: Detection of Cyanobacteria in Eutrophic Water Using a Portable Electrocoagulator and NanoGene Assay Environ. Sci. Technol. 2018, 52(3):1375-1385.

26. Edgar R: UPARSE: highly accurate OTU sequences from microbial amplicon reads Nat. Methods. 2013, 10: 996-998.

27. James RC, Qiong W, Jordan A, et al: Ribosomal Database Project: data and tools for high throughput rRNA analysis Nucl. Acids Res. 2014, 42: 633-642.

28. Qiong W, George M, James M, et al: Naïve Bayesian Classifier for Rapid Assignment of rRNA Sequences into the New Bacterial Taxonomy Appl. Environ. Microbiol. 2007, 73(16): 5261-5267.

29. Paul FK, Josephine YA: Bacterial diversity in aquatic and other environments:what 16S rDNA libraries can tell us FEMS Microbiol.Ecol. 2004, 47:161-177.

30. Segata N, Izard J, Waldron L, et al: Metagenomic biomarker discovery and explanation Genome Biol. 2011, 12: 60.

\section{Figures}



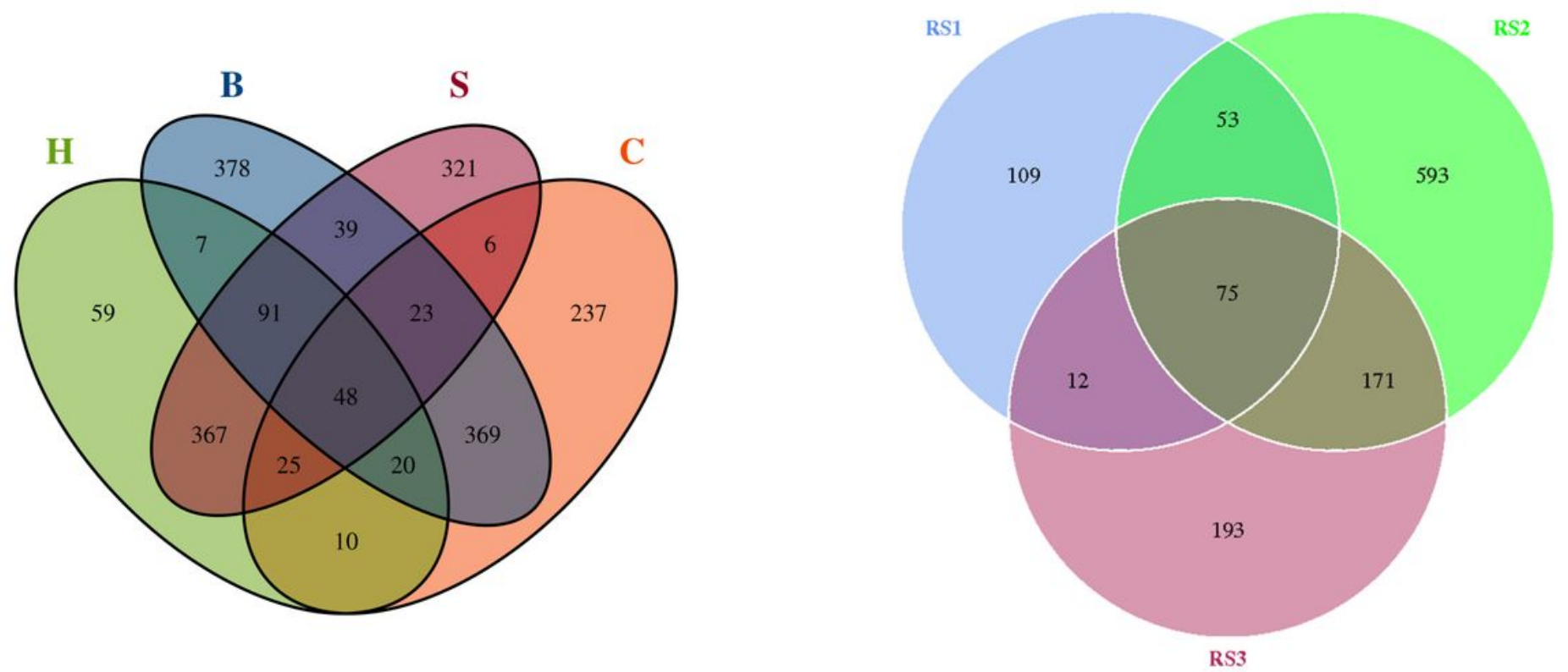

\section{Figure 1}

Venn diagram. Veen diagram reflected the number of core OTUs and special OTUs at two years. ( $\mathrm{H}, \mathrm{B}, \mathrm{S}$ and $\mathrm{C}$ represents aquatic plants planktonic flora, water planktonic flora, Organ microbiota, gut microbiota in 2018, respectively. And RS1, RS2 and RS3 represents feces planktonic flora, water planktonic flora and aquatic plants planktonic flora in 2019 , respectively. ) 
a.

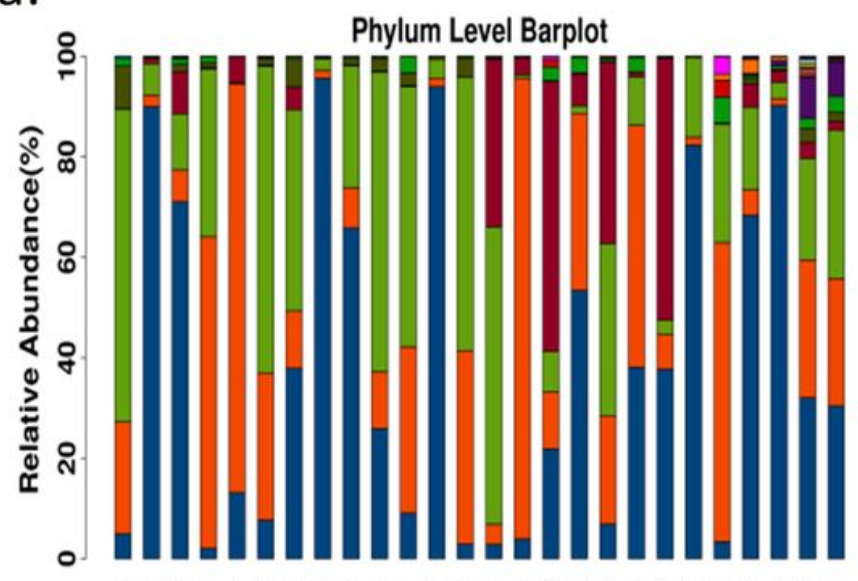

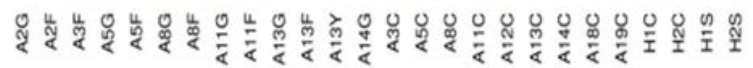

b.

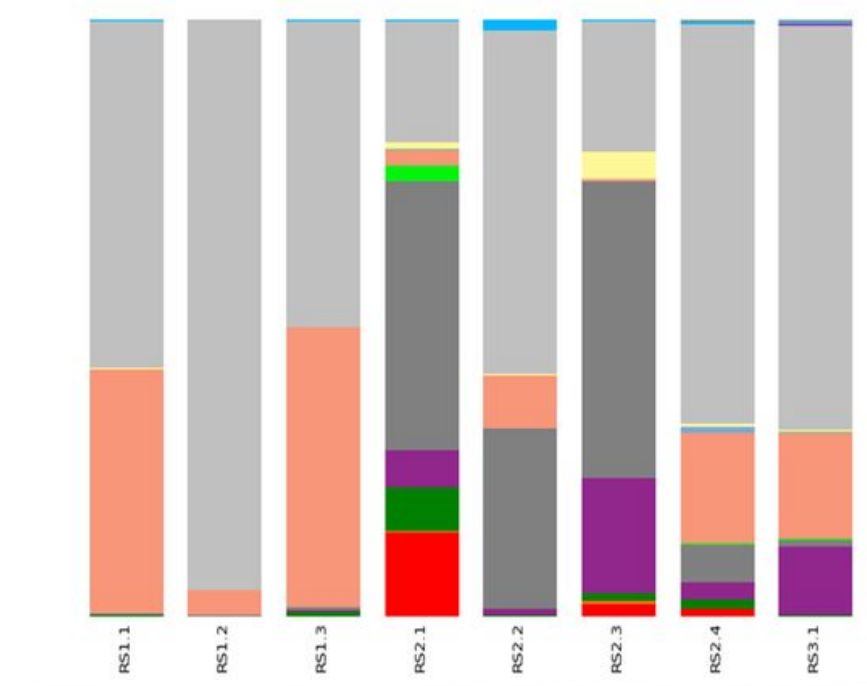

Figure 2

\begin{tabular}{|c|c|c|}
\hline Proteobacteria & Spirochaetes & Euryarchaeota \\
\hline Firmicutes & Tenericutes & Chloroflexi \\
\hline Bacteroidetes & Deforribacteres & SRI \\
\hline Fusobacteria & Deinococcus-Thermus & Fibrobacteres \\
\hline Verrucomicrobia & Candidatus Saccharibacteria & IIII Synergistetes \\
\hline Actinobacteria & Gemmatimonadetes & Armatimonadetes \\
\hline Cyanobacteria Chloroplast & Acidobacteria & Other \\
\hline
\end{tabular}

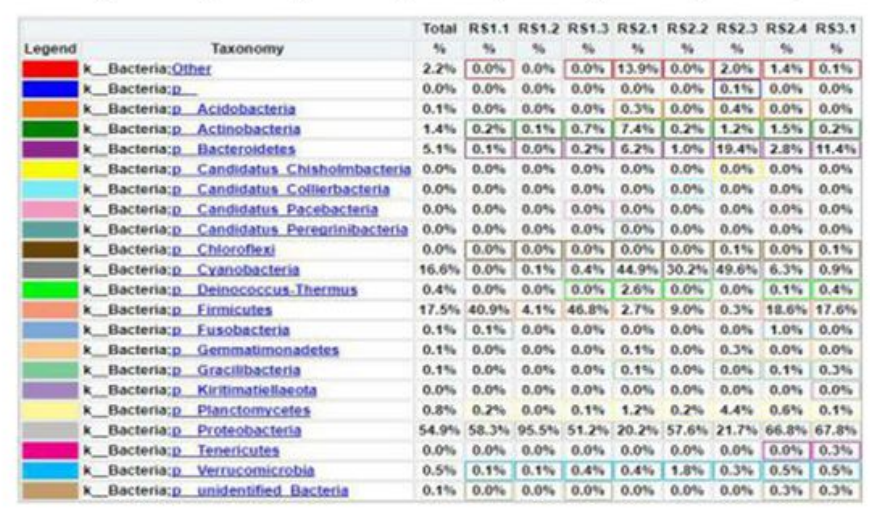

Microbial species richness and diversity. a: the bacteria richness and diversity of 16S rDNA samples at phylum level in 2018. b: the bacteria richness and diversity of 16S rDNA samples at phylum level in 2019.
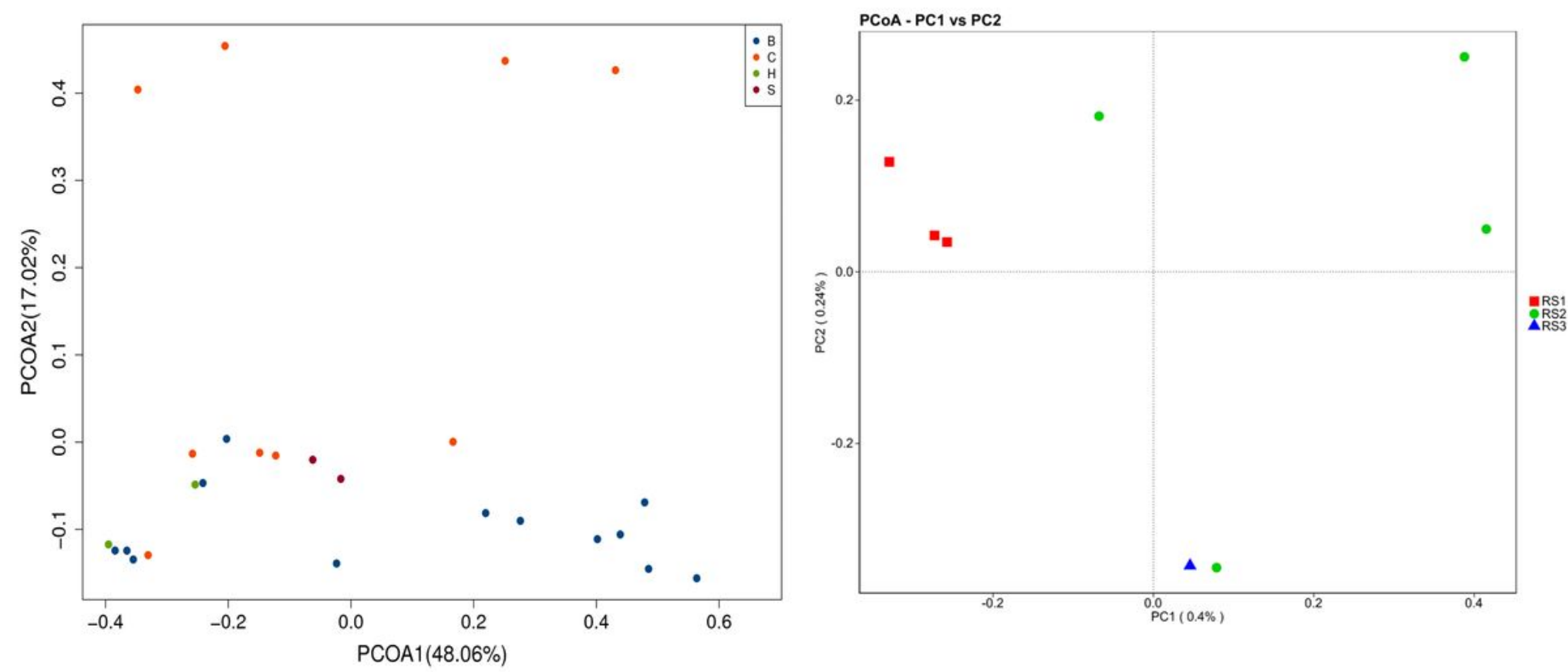


\section{Figure 3}

weighted unifrac PCoA. H, B, S and C represents aquatic plants planktonic flora, water planktonic flora, Organ microbiota, gut microbiota in 2018, respectively. And RS1, RS2 and RS3 represents feces planktonic flora, water planktonic flora and aquatic plants planktonic flora in 2019, respectively.

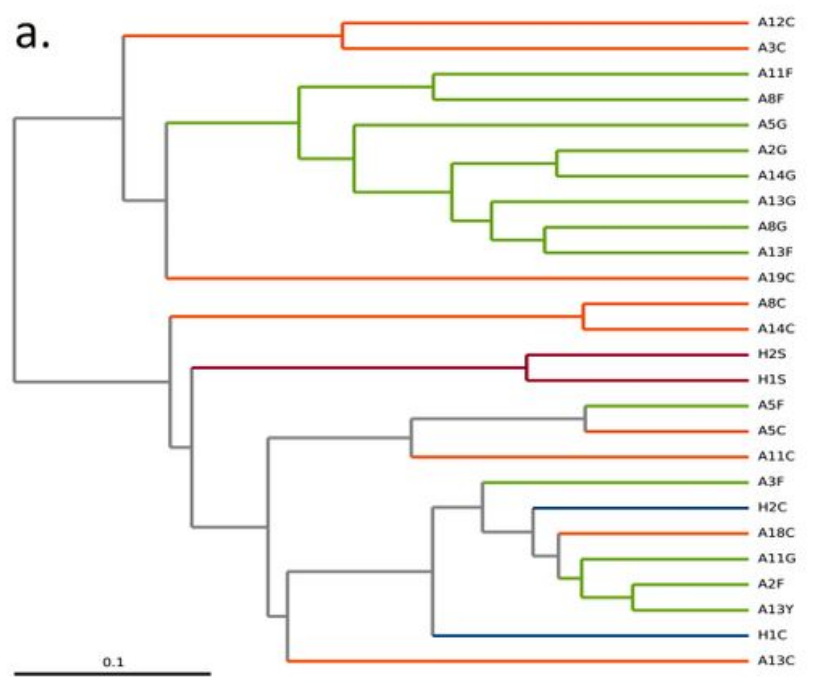

b.

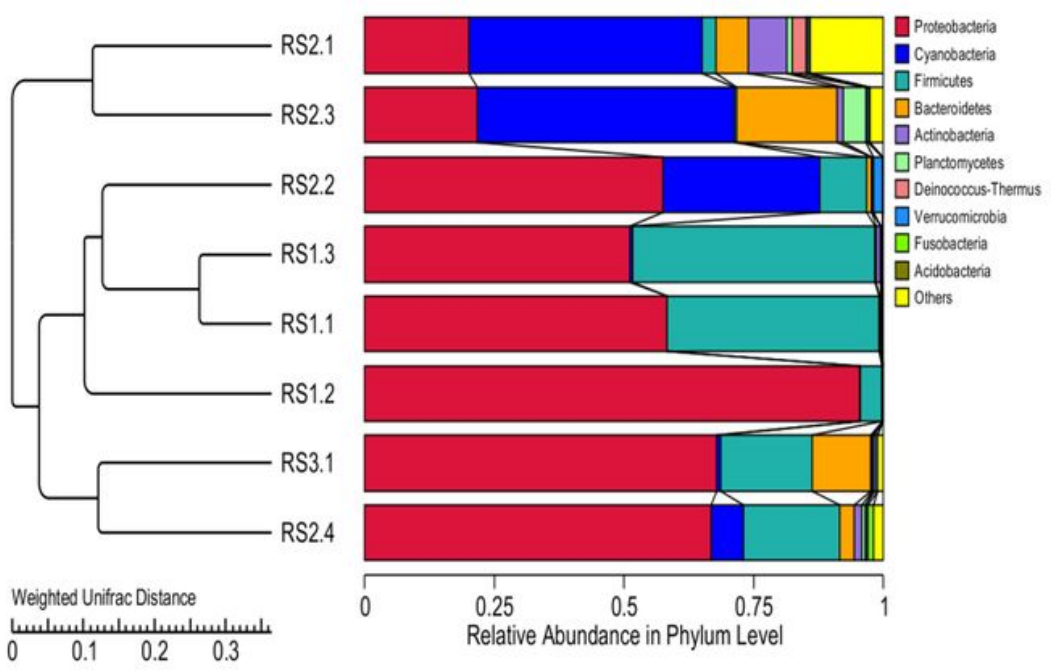

\section{Figure 4}

Unweighted pair group method with arithmetic mean. Bacterial community structural dynamics at the phylum level by an unweighted pair group method with arithmetic mean (UPGMA) tree, based on weighted UniFrac distances. a: the weighted UniFrac of 16 S rDNA samples at phylum level in 2018. b: the weighted UniFrac of 16S rDNA samples at phylum level in 2019. 
a.

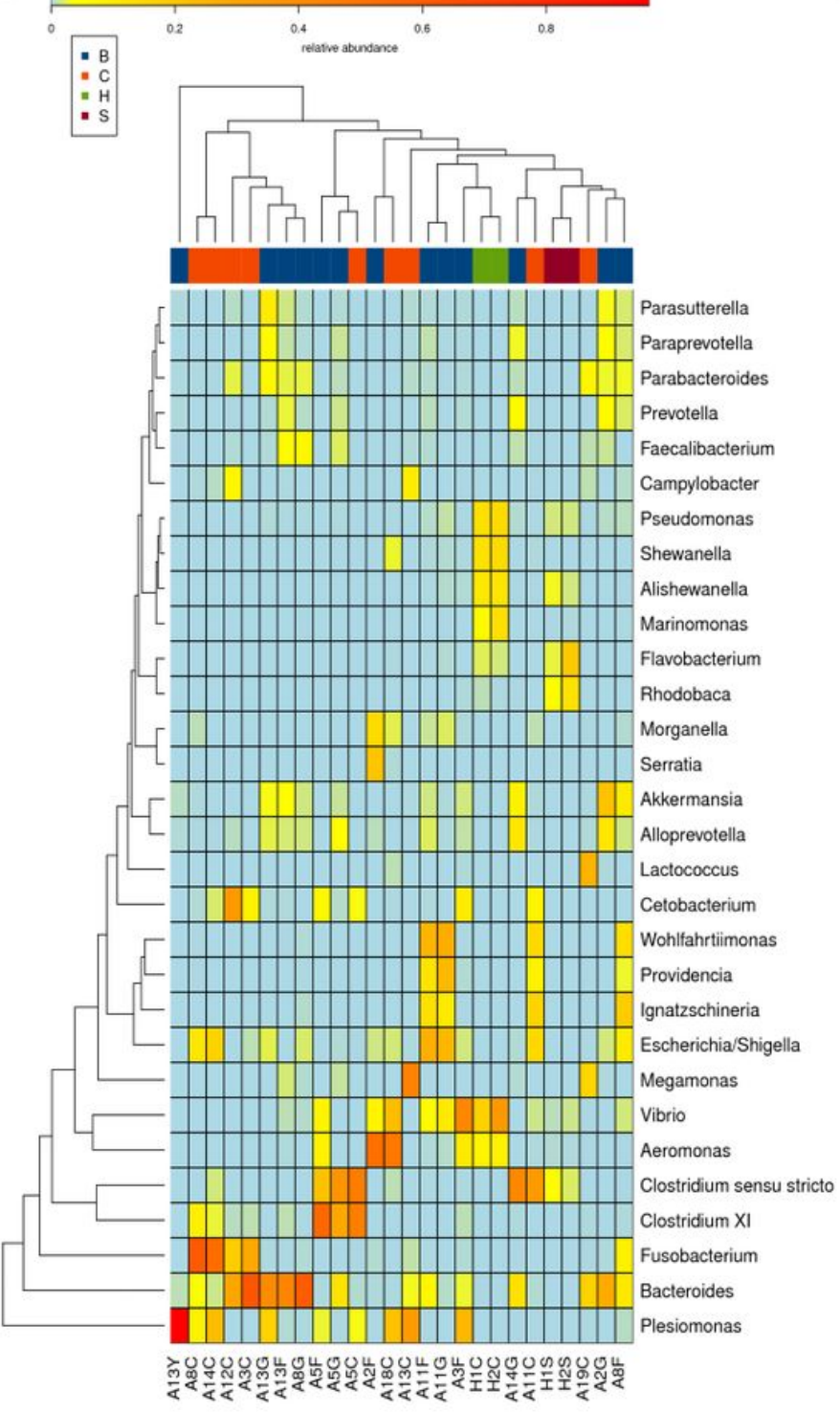

b.

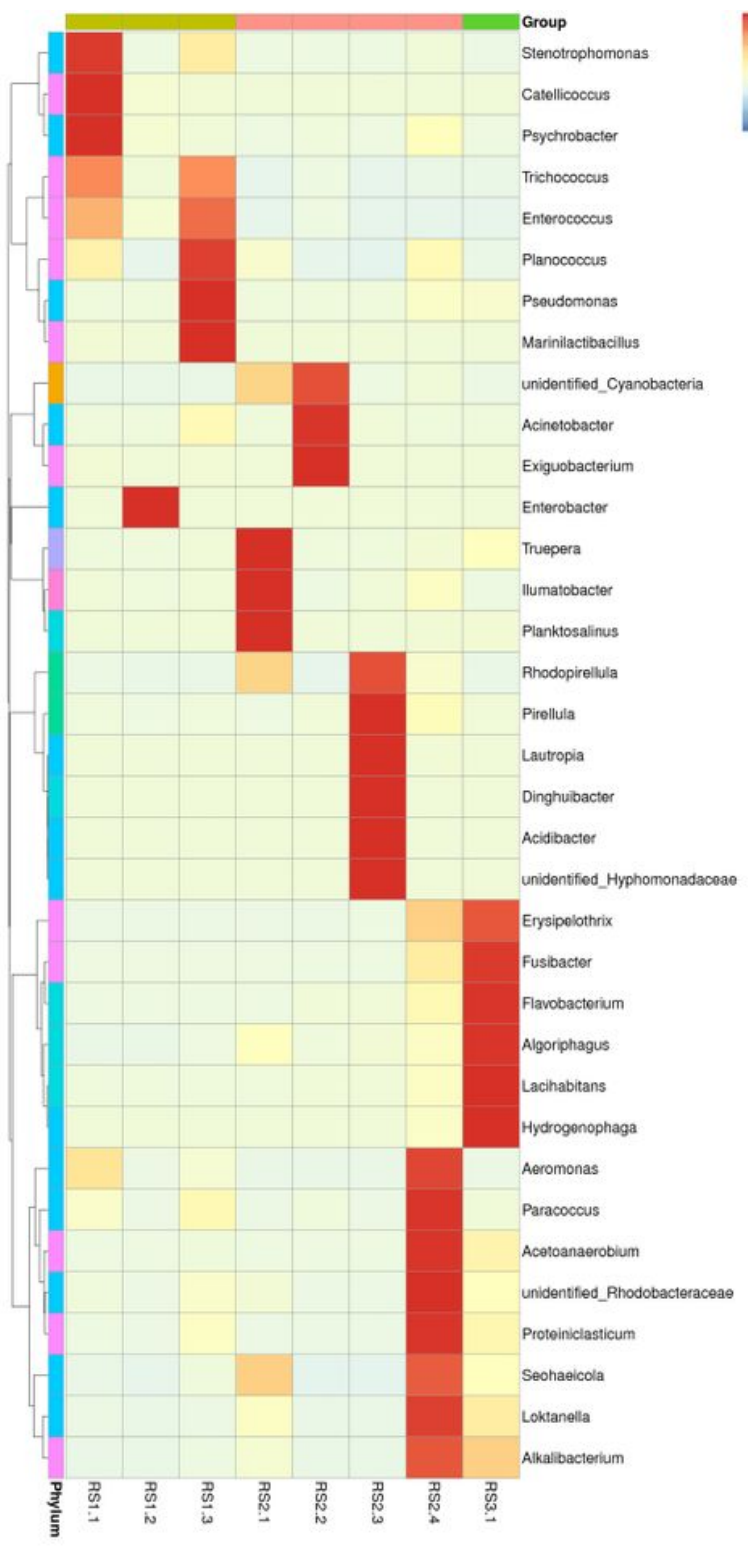

Figure 5

The cluster heatmap analysis of different functional areas. a: the heatmap of 30 main genus in samples, 2018. b: the heatmap of 30 main genus in samples, 2019. The darker the color, the higher the relative abundance.

\section{Supplementary Files}

This is a list of supplementary files associated with this preprint. Click to download.

- SupplementTableS1weightedPCoAinformation.xls

- SupplementTableS2LDAinformationfrom2018to2019..xls

- SupplementTableS30TUsspeciesclassification.xls

- SupplementFigureS1Taxonomictree.doc

- SupplementFigureS2LEfSe.doc 